NBER WORKING PAPER SERIES

\title{
THE IMPACT OF PUBLIC AND PRIVATE RESEARCH SUPPORT ON PREMATURE CANCER MORTALITY AND HOSPITALIZATION IN THE U.S., 1999-2013
}

\author{
Frank R. Lichtenberg \\ Working Paper 23241 \\ http://www.nber.org/papers/w23241 \\ NATIONAL BUREAU OF ECONOMIC RESEARCH \\ 1050 Massachusetts Avenue \\ Cambridge, MA 02138 \\ March 2017
}

The views expressed herein are those of the author and do not necessarily reflect the views of the National Bureau of Economic Research.

NBER working papers are circulated for discussion and comment purposes. They have not been peer-reviewed or been subject to the review by the NBER Board of Directors that accompanies official NBER publications.

(C) 2017 by Frank R. Lichtenberg. All rights reserved. Short sections of text, not to exceed two paragraphs, may be quoted without explicit permission provided that full credit, including () notice, is given to the source. 
The Impact of Public and Private Research Support on Premature Cancer Mortality and Hospitalization in the U.S., 1999-2013

Frank R. Lichtenberg

NBER Working Paper No. 23241

March 2017

JEL No. I10,I18,J11,O3

\begin{abstract}
$\underline{\text { ABSTRACT }}$
We use data from PubMed and other sources to examine the impact of public and private research support on premature (before ages 75, 65, and 55) cancer mortality and hospitalization, by estimating difference-in-differences models based on longitudinal, cancer-site-level data on about 30 cancer sites.

The estimates indicate that cancer sites about which more research-supported articles were published since the 1970s had larger reductions in premature mortality and hospitalization during the period 1999-2013, controlling for the change in the number of people diagnosed. Cancer sites for which more non-research-supported articles were published did not have larger reductions in premature mortality or hospitalization.

The research support that contributed to articles published during 1987-2001 reduced premature (before age 75) mortality at an average annual rate of $0.9 \%$ during the period 1999-2013, and it reduced the number of years of potential life lost before age 75 due to cancer in 2013 by 566 thousand. The research support that contributed to articles published during 1984-1998 reduced hospital discharges at an average annual rate of 4.1\% during the period 1999-2013, and it reduced the number of hospital discharges due to cancer in 2013 by 566 thousand.
\end{abstract}

Frank R. Lichtenberg

Columbia University

504 Uris Hall

3022 Broadway

New York, NY 10027

and NBER

frl1@columbia.edu 


\section{Introduction}

In a previous study, Lichtenberg (2013) used PubMed ${ }^{1}$ data on the number of publications about different types of cancer (breast, colon, lung, etc.) to provide evidence about the impact of biomedical research on U.S. cancer mortality rates. ${ }^{2}$ Estimates from that study indicated that mortality rates: (1) are unrelated to the (current or lagged) stock of publications that had not received research funding; (2) are only weakly inversely related to the contemporaneous stock of published articles that received research funding; and (3) are strongly inversely related to the stock of articles that had received research funding and been published 5 and 10 years earlier.

In this paper, we will extend and update the analysis performed in Lichtenberg (2013) in a number of important respects:

- The sole outcome measure analyzed in the previous study was the age-adjusted mortality rate. In this paper, we will analyze a different type of mortality measure: years of potential life lost (YPLL) before three ages $\left(75,65\right.$, and 55). ${ }^{3}$ Estimates of YPLL models (but not of age-adjusted mortality rate models) enable us to calculate the number of lifeyears gained from biomedical research.

- In addition to analyzing the impact of biomedical research on premature cancer mortality, we will analyze its effect on hospitalization (the number of inpatient hospital discharges and days of care) due to cancer. Hospital care was the largest single component of U.S. medical expenditure in 2014, accounting for 32\% of total expenditure (Centers for Medicare \& Medicaid Services (2017)).

\footnotetext{
${ }^{1}$ PubMed comprises over 26 million citations for biomedical literature from MEDLINE, life science journals, and online books. PubMed citations and abstracts include the fields of biomedicine and health, covering portions of the life sciences, behavioral sciences, chemical sciences, and bioengineering. PubMed also provides access to additional relevant web sites and links to the other NCBI molecular biology resources. PubMed is a free resource that is developed and maintained by the National Center for Biotechnology Information (NCBI), at the U.S. National Library of Medicine (NLM), located at the National Institutes of Health (NIH).

${ }^{2}$ Previous research on the agricultural (Evenson and Kislev (1973)) and manufacturing (Adams (1990)) sectors of the economy had found that counts of publications are useful indicators of the stock of knowledge.

${ }^{3}$ Previous authors have argued that "reducing premature mortality is a crucial public health objective" (Renard, Tafforeau, and Deboosere (2014)). A widely used measure of premature mortality is years of potential life lost (YPLL) before a given age (e.g. age 75), i.e. the number of years not lived by an individual who died before that age (Association of Public Health Epidemiologists in Ontario (2015)). Statistics of YPLL are published by the World Health Organization, the OECD, and government agencies of the U.S., Switzerland, and other countries. Burnet et al (2005) argue that YPLL "should be considered when allocating research funds."
} 
- The previous study controlled for changes in incidence by including just the contemporaneous age-adjusted incidence rate (in year $\mathrm{t}$ ) in the age-adjusted mortality model. In this paper, we will control for the average annual number of patients diagnosed in years t-9 to $\mathrm{t}$ in the premature mortality and hospitalization models.

- In the previous study, all publications in which a specific type of cancer was a topic were included. In this paper, only publications in which a specific type of cancer was one of the main topics are included. ${ }^{4}$

- In the previous study, the maximum allowed lag from publication to mortality was 10 years. In this paper, we allow for lags of up to 24 years.

- The functional form specified in the previous study was log-log. In this paper, we will estimate semi-logarithmic models. Comparison of the marginal effects of research-based and non-research-based publications is more straightforward in the semi-logarithmic model.

- In the previous study, the sample period was 1995-2009. This paper will analyze a more recent period: 1999-2013.

In the next section of this paper, we describe the econometric model of premature mortality and hospitalization that we will estimate. In Section III, we describe the data sources we rely upon to construct the dataset used to estimate the model and present descriptive statistics; all of the data are publicly available. Estimates of the models are presented in Section IV. Implications of the estimates are discussed in Section V. Section VI contains a summary and conclusions.

\section{Econometric model of premature mortality and hospitalization}

To assess the impact of biomedical research on premature cancer mortality and hospitalization, I will estimate the following difference-in-differences model based on longitudinal, cancer-site-level data on about 30 cancer sites:

\footnotetext{
${ }^{4}$ As of 4 March 2017, "breast neoplasms" was a topic in 247,546 publications, and was a "main topic" in 207,485 publications; "colonic neoplasms" was a topic in 67,435 publications, and was a "main topic" in 49,940 publications.
} 


$$
\begin{gathered}
\ln \left(\mathrm{Y}_{\mathrm{st}}\right)=\beta_{\text {research }} \text { CUM_RESEARCH_PUBS } \mathrm{s}_{\mathrm{s}, \mathrm{t}-\mathrm{k}}+\beta_{\text {other }} \text { CUM_OTHER_PUBS } \mathrm{s}_{\mathrm{s}, \mathrm{t}-\mathrm{k}} \\
+\gamma \ln \left(\mathrm{CASES}_{-} 10 \_\mathrm{YEARS}_{\mathrm{st}}\right)+\alpha_{\mathrm{s}}+\delta_{\mathrm{t}}+\varepsilon_{\mathrm{st}}
\end{gathered}
$$

where $\mathrm{Y}_{\text {st }}$ is one of the following variables:

YPLL 75 $_{\mathrm{st}}=$ the number of years of potential life lost before age 75 from cancer at site $\mathrm{s}(\mathrm{s}=1, \ldots, 30)$ in year $\mathrm{t}(\mathrm{t}=1999, \ldots, 2013)$

YPLL65 $_{\text {st }}=$ the number of years of potential life lost before age 65 from cancer at site $\mathrm{s}$ in year $\mathrm{t}$

YPLL55 $_{\mathrm{st}}=$ the number of years of potential life lost before age 55 from cancer at site $\mathrm{s}$ in year $\mathrm{t}$

DISCHARGES $_{\text {st }}=$ the number of inpatient hospital discharges in year $t$ for which the principal diagnosis was cancer at site $\mathrm{s}$

HOSP_DAYS st $_{\text {L }}=$ the number of days of inpatient hospital care in year $\mathrm{t}$ for which the principal diagnosis was cancer at site $\mathrm{s}$

and

$$
\begin{aligned}
& \text { CUM_RESEARCH_PUBS } \mathrm{s}_{\mathrm{s}, \mathrm{t}-\mathrm{k}}=\text { the number of PubMed articles published by the end of } \\
& \text { year } \mathrm{t}-\mathrm{k}(\mathrm{k}=0,3,6, \ldots, 24) \text { that had cancer at site } \mathrm{s} \text { as a } \\
& \text { "main topic" and that mentioned U.S. Government and/or } \\
& \text { non-U.S. Government research support }{ }^{5} \\
& \text { CUM_OTHER_PUBS } \mathrm{s}_{\mathrm{s}, \mathrm{t}-\mathrm{k}}=\text { the number of PubMed articles published by the end of } \\
& \text { year } \mathrm{t}-\mathrm{k} \text { that had cancer at site } \mathrm{s} \text { as a "main topic" and that } \\
& \text { did not mention either U.S. Government or non-U.S. } \\
& \text { Government research support } \\
& \alpha_{\mathrm{s}}=\mathrm{a} \text { fixed effect for cancer at site } \mathrm{s} \\
& \delta_{\mathrm{t}}=\mathrm{a} \text { fixed effect for year } \mathrm{t}
\end{aligned}
$$

\footnotetext{
${ }^{5}$ Disentangling the effects of U.S. Government and non-U.S. Government research support is difficult. As shown in Lichtenberg (2013), almost half of the publications that cite U.S. Government research support also cite non-U.S. Government research support. Non-U.S. government financial support includes support by American societies, institutes, state governments, universities, and private organizations, and by foreign sources (national, departmental, provincial, academic \& private organizations).
} 


$$
\varepsilon_{\text {st }}=\text { a disturbance }
$$

The fixed year effects control for time-varying factors that influence cancer mortality and hospitalization in general. The models will be estimated by weighted least squares, weighting by (1/15) $\Sigma_{\mathrm{t}} \mathrm{Y}_{\mathrm{st}}$. Disturbances will be clustered within cancer sites.

\section{Data sources and descriptive statistics}

Premature mortality data. Data on the number of years of potential life lost before ages 75, 65, and 55, by cancer site and year, were constructed from data contained in the WHO Mortality Database. Data for 1999 and 2013 are shown in Table 1. Figure 1 shows data on the number of years of potential life lost before age 75 in 1999 and 2013 for 4 cancer sites that had roughly similar numbers (between 141 and 196 thousand) of YPLL75 in 1999. The 1999-2013 change in YPLL75 varied considerably across these 4 cancer sites.

Hospitalization data. Data on the number of inpatient hospital discharges and days of care, by cancer site and year, were constructed from data contained in the Healthcare Cost and Utilization Project (Agency for Healthcare Research and Quality (2017)). The number of days of care was computed as the number of discharges times average length of stay. Data for 1999 and 2013 are shown in Table 2.

Research-based and other publications. Data on CUM_RESEARCH_PUBS and CUM_OTHER_PUBS, by cancer site and year, were constructed by performing searches on the PubMed Advanced Search Builder. As shown in Appendix Table 1, this tool allows the user to download data on the number of results (publications) by year after performing a search. We used the diseases branch (D) of the MeSH Tree to determine appropriate search terms (cancer site definitions). A publication was included in CUM_RESEARCH_PUBS if it had any one of the following "Publication Types": Research Support, American Recovery and Reinvestment Act; Research Support, N.I.H., Extramural; Research Support, N.I.H., Intramural; Research Support, Non-U.S. Gov't; Research Support, U. S. Gov't; Research Support, U.S. Gov't, NonP.H.S.; Research Support, U.S. Gov't, P.H.S. Data for 1999 and 2013 are shown in Table 3. Figure 2 shows data on the cumulative number of research-supported publications in 1989, 2001, and 2013 for 4 cancer sites that had similar numbers (between 4261 and 4678) of research- 
supported publications in 1989. The number of research-supported articles published during 1990-2013 varied considerably across these 4 cancer sites.

Incidence data. Data on the number of people diagnosed in SEER 9 registries, by cancer site and year, were obtained from the National Cancer Institute's SEER*Stat Software. Data for 1999 and 2013 are shown in Table 4.

\section{Empirical results}

Estimates of parameters of premature mortality models (eq. (1), where Y $=$ YPLL75, YPLL65, or YPLL55) are shown in Table 5. Each row of the table represents a separate model, corresponding to a different dependent variable and assumed lag length $(\mathrm{k})$ from publications to premature mortality. CUM_RESEARCH_PUBS and CUM_OTHER_PUBS are both measured in thousands.

In lines $1-9$, the dependent variable is $\ln ($ YPLL75), and $k=0,3,6, \ldots, 24$, respectively.

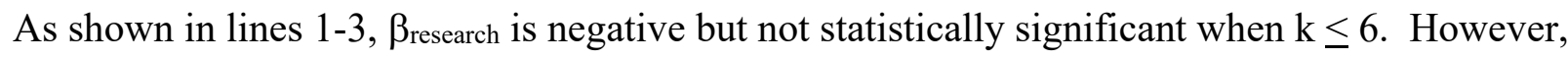

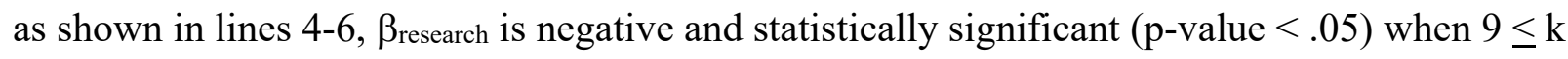
$\leq 15$. This indicates that premature (before age 75) mortality is inversely related to the number of research-supported articles that had been published 9-15 years earlier, controlling for the number of other articles that had been published 9-15 years earlier and for the average annual number of patients diagnosed in SEER 9 registries in the previous 10 years. The estimate in line 5 implies that 1000 additional research-supported publications is associated with a $1.3 \%$ YPLL75 reduction 12 years later. The point estimates of $\beta_{\text {research }}$ when $18 \leq \mathrm{k} \leq 24$ are similar to the point estimates when $9 \leq \mathrm{k} \leq 15$, but the standard errors are much larger when $18 \leq \mathrm{k} \leq 24$, so those estimates are not statistically significant. ${ }^{6}$ The estimates of $\beta_{\text {research for }} 0 \leq \mathrm{k} \leq 24$ from $\ln$ (YPLL75) models are shown (on an inverted scale) in Figure 3.

None of the estimates of $\beta_{\text {other }}$ in lines 1-9 are statistically significant: premature (before age 75) mortality is unrelated to the number of publications that did not mention either U.S. Government or non-U.S. Government research support. All of the estimates of $\gamma$ in lines 1-9 are

\footnotetext{
${ }^{6}$ The large standard errors may be attributable, to an important extent, to left-censoring of the data on researchsupported articles: PubMed did not record information about research support until 1975 (National Library of Medicine (2017)).
} 
statistically significant: YPLL75 is significantly positively related to the number of people diagnosed in the previous 10 years.

In lines 10-18 of Table 5 , the dependent variable is $\ln$ (YPLL65). These estimates are quite similar to the estimates in lines 1-9. PYLL65 is inversely related to the number of research-supported articles that had been published 12-15 years earlier, and is unrelated to the number of other articles. It is also unrelated to the number of people diagnosed in the previous 10 years, presumably because about half of cancer patients are diagnosed after the age of $65 .{ }^{7}$

In lines 19-27 of Table 5, the dependent variable is $\ln$ (YPLL55). The estimates of

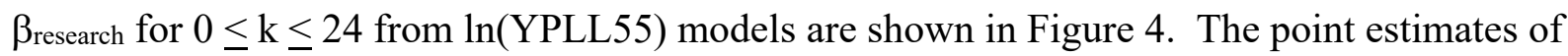
$\beta_{\text {research }}$ are strictly increasing with respect to lag length. The estimates for $0 \leq \mathrm{k} \leq 15$ are not statistically significant, but the estimates for $18 \leq \mathrm{k} \leq 24$ are statistically significant. This indicates that the number of years of potential life lost before age 55 is inversely related to the number of research-supported articles that had been published 18-24 years earlier, and that 1000 additional research-supported publications is associated with a 4.2\% YPLL55 reduction 24 years later. Evidently, the lag from research-supported publications to premature mortality reduction is considerably longer for YPLL55 than it is for YPLL75.

Estimates of parameters of hospitalization models (eq. (1), where $\mathrm{Y}=$ DISCHARGES or HOSP_DAYS) are shown in Table 6. In lines 1-9, the dependent variable is $\ln ($ DISCHARGES). The estimates of $\beta_{\text {research }}$ for $0 \leq \mathrm{k} \leq 24$ from $\ln$ (DISCHARGES) models are shown in Figure 5. For all values of $\mathrm{k}$, the estimate is negative and statistically significant. Once again, the point estimates of $\beta_{\text {research }}$ are strictly increasing with respect to lag length. The estimate of $\beta_{\text {research }}$ in line 9 of Table 6 indicates that 1000 additional research-supported publications is associated with a 10\% DISCHARGES reduction 24 years later. The estimates in lines 1-9 indicate that the number of hospital discharges is significantly positively related to the number of people diagnosed in the previous 10 years, as expected. The estimates also indicate that the number of hospital discharges is also significantly positively related to the number of other (non-researchsupported) publications, which is somewhat surprising. However, the magnitudes of the $\beta_{\text {other }}$ coefficients are much smaller than the magnitudes of the $\beta_{\text {research }}$ coefficients: the estimate of

\footnotetext{
${ }^{7}$ https://www.cancer.gov/about-cancer/causes-prevention/risk/age
} 
$\beta_{\text {other }}$ in line 9 indicates that 1000 additional non-research-supported publications is associated with only a $1.6 \%$ DISCHARGES increase 24 years later.

In lines 10-18, the dependent variable is $\ln ($ HOSP_DAYS). Estimates of the parameters of HOSP_DAYS models are quite similar to estimates of the parameters of DISCHARGES models.

\section{Discussion}

The estimates of eq. (1) indicate that cancer sites about which more research-supported articles were published since the 1970s had larger reductions in premature mortality and hospitalization during the period 1999-2013, controlling for the change in the number of people diagnosed. Cancer sites for which more non-research-supported articles were published did not have larger reductions in premature mortality or hospitalization.

We can use the estimates to calculate the reduction in premature mortality in 2013 attributable to previous publication of research-supported articles. Lines 1-9 of Table 5 indicate

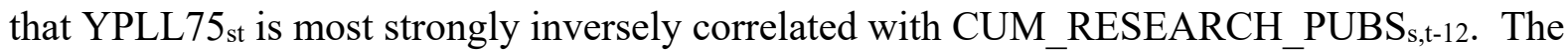
weighted (by $(1 / 15) \Sigma_{\mathrm{t}}$ YPLL75 $_{\mathrm{st}}$ ) mean 1999-2013 increase in CUM_RESEARCH_PUBS $\mathrm{s}_{\mathrm{s}, \mathrm{t}-12}$ was $9.01(=12.13-3.11)$. The estimate of $\beta_{\text {research }}$ in the YPLL75 model when $\mathrm{k}=12$ is -0.013 , so we estimate that, if no research-supported articles had been published during the period 19872001, the number of years of potential life lost before age 75 due to cancer in 2013 would have been $12.8 \%(=\exp (0.013 * 9.01)-1)$ higher. Since previous research reduced YPLL75 by $12.8 \%$ over a 14 -year period, it reduced premature mortality at an average annual rate of $0.9 \%(=$ $12.8 \%$ / 14). According to the Centers for Disease Control (2017), 4407 thousand years of potential life were lost before age 75 due to cancer in 2013, so we estimate that, if no researchsupported articles had been published during the period 1987-2001, the number of years of potential life lost before age 75 due to cancer in 2013 would have been 566 thousand $(=12.8 \%$ * 4407 thousand) higher.

We can also use the estimates to calculate the reduction in hospital discharges in 2013 attributable to previous publication of research-supported articles. Lines 1-9 of Table 6 indicate

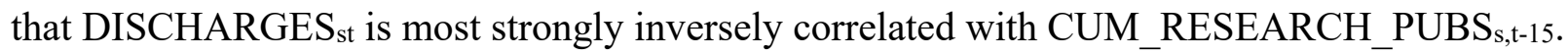
The weighted (by $(1 / 15) \Sigma_{\mathrm{t}}$ DISCHARGES $_{\mathrm{st}}$ ) mean 1999-2013 increase in 
CUM_RESEARCH_PUBS $\mathrm{s}, \mathrm{t}-15$ was $7.31(=9.17-1.86)$. The estimate of $\beta_{\text {research }}$ in the DISCHARGES model when $\mathrm{k}=15$ is -0.062 , so we estimate that, if no research-supported articles had been published during the period 1984-1998, the number of hospital discharges due to cancer in 2013 would have been $57.0 \%(=\exp (0.062 * 7.31)-1)$ higher. Since previous research reduced DISCHARGES by $57.0 \%$ over a 14-year period, it reduced hospital discharges at an average annual rate of $4.1 \%(=57.0 \% / 14)$. According to HCUPnet (2017), there were 1082 thousand hospitalizations due to cancer in 2013, so we estimate that, if no researchsupported articles had been published during the period 1984-1998, the number of hospital discharges due to cancer in 2013 would have been 566 thousand (=57.0\% * 1082 thousand) higher.

\section{Summary and conclusions}

A previous study used PubMed data on the number of publications about different types of cancer (breast, colon, lung, etc.) to provide evidence about the impact of biomedical research on U.S. cancer mortality rates. In this paper, we extended and updated the analysis performed in the earlier study in several important respects: we analyzed a different type of mortality measure (years of potential life lost (YPLL) before three ages $(75,65$, and 55)); we analyzed the effect of research-supported publications on hospitalization as well as on mortality; we controlled for lagged as well as current cancer incidence; and we allowed for longer ( 24 years vs. 10 years) lags from publication to cancer outcomes.

To assess the impact of biomedical research on premature cancer mortality and hospitalization, we estimated difference-in-differences models based on longitudinal, cancer-sitelevel data on about 30 cancer sites. The estimates indicated that cancer sites about which more research-supported articles were published since the 1970s had larger reductions in premature mortality and hospitalization during the period 1999-2013, controlling for the change in the number of people diagnosed. Cancer sites for which more non-research-supported articles were published did not have larger reductions in premature mortality or hospitalization.

Premature (before age 75) mortality is inversely related to the number of researchsupported articles that had been published 9-15 years earlier, controlling for the number of other articles that had been published 9-15 years earlier and for the average annual number of patients diagnosed in SEER 9 registries in the previous 10 years. The estimates indicated that 1000 
additional research-supported publications is associated with a 1.3\% YPLL75 reduction 12 years later. Estimates of models of YPLL65 were quite similar to estimates of models of YPLL75. YPLL65 is inversely related to the number of research-supported articles that had been published 12-15 years earlier, and is unrelated to the number of other articles.

The number of years of potential life lost before age 55 is inversely related to the number of research-supported articles that had been published 18-24 years earlier; 1000 additional research-supported publications is associated with a 4.2\% YPLL55 reduction 24 years later. Evidently, the lag from research-supported publications to premature mortality reduction is considerably longer for YPLL55 than it is for YPLL75.

The number of hospital discharges attributed to cancer is significantly inversely related to the number of research-supported articles at every lag length investigated (from 0 to 24 years), but the magnitude of the effect is strictly increasing with respect to lag length. The estimates indicated that 1000 additional research-supported publications is associated with a $10 \%$ reduction in hospital discharges 24 years later.

The research support that contributed to articles published during 1987-2001 reduced premature (before age 75) mortality at an average annual rate of $0.9 \%$ during the period 1999 2013 , and it reduced the number of years of potential life lost before age 75 due to cancer in 2013 by 566 thousand. The research support that contributed to articles published during 19841998 reduced hospital discharges at an average annual rate of 4.1\% during the period 1999-2013, and it reduced the number of hospital discharges due to cancer in 2013 by 566 thousand.

\section{References}

Adams JD (1990), "Fundamental Stocks of Knowledge and Productivity Growth," Journal of Political Economy 98 (4): 673-702, August.

Agency for Healthcare Research and Quality (2017). HCUPnet: A tool for identifying, tracking, and analyzing national hospital statistics.

Association of Public Health Epidemiologists in Ontario (2015). Calculating Potential Years of Life Lost (PYLL), http://www.apheo.ca/index.php?pid=190

Burnet NG, Jefferies SJ, Benson RJ, Hunt DP, Treasure FP (2005). Years of life lost (YLL) from cancer is an important measure of population burden--and should be considered when allocating research funds. British Journal of Cancer 92 (2): 241-5, January, http://www.ncbi.nlm.nih.gov/pmc/articles/PMC2361853/ 
Centers for Disease Control (2017), Years of Potential Life Lost (YPLL) Reports, 1999 - 2015.

Centers for Medicare \& Medicaid Services, Office of the Actuary, National Health Statistics Group (2017), The Nation's Health Dollar (\$3.0 Trillion), Calendar Year 2014, Where It Went.

Evenson RE, Kislev Y (1973). Research and Productivity in Wheat and Maize. Journal of Political Economy 81(6): 1309-29.

Lichtenberg F (2013). The impact of biomedical research on U.S. cancer mortality: a bibliometric analysis, NBER Working Paper No. 19593, October; forthcoming in Measuring and Modeling Health Care Costs, Ana Aizcorbe, Colin Baker, Ernst Berndt, and David Cutler, editors (University of Chicago Press, NBER Book Series Studies in Income and Wealth).

National Library of Medicine (2017), Funding Support (Grant) Information in MEDLINE/PubMed.

Renard F, Tafforeau J, Deboosere P (2014). Premature mortality in Belgium in 1993-2009: leading causes, regional disparities and 15 years change. Arch Public Health 72(1): 34, Oct 1. 
Table 1

Number of years of potential life lost before ages 75, 65, and 55, by cancer site, 1999 and 2013

\begin{tabular}{|c|c|c|c|c|c|c|}
\hline \multirow[t]{2}{*}{ Cancer site } & \multicolumn{2}{|c|}{ YPLL75 } & \multicolumn{2}{|c|}{ YPLL65 } & \multicolumn{2}{|c|}{ YPLL55 } \\
\hline & 1999 & 2013 & 1999 & 2013 & 1999 & 2013 \\
\hline Respiratory Tract Neoplasms & $1,094,462$ & $1,039,040$ & 386,680 & 339,215 & 96,512 & 64,067 \\
\hline Breast Neoplasms & 420,346 & 399,430 & 209,158 & 182,937 & 78,561 & 60,710 \\
\hline Colonic Neoplasms & 275,970 & 289,895 & 110,322 & 120,808 & 35,542 & 37,203 \\
\hline Genital Neoplasms, Female & 235,153 & 270,230 & 112,295 & 117,903 & 43,355 & 39,580 \\
\hline Nervous System Neoplasms & 196,118 & 210,359 & 115,921 & 115,574 & 63,378 & 59,851 \\
\hline Pancreatic Neoplasms & 188,112 & 250,760 & 72,090 & 86,768 & 20,067 & 19,098 \\
\hline Lymphoma, Non-Hodgkin & 167,540 & 117,849 & 78,995 & 49,712 & 33,860 & 19,272 \\
\hline Urologic Neoplasms & 141,558 & 167,829 & 56,698 & 60,934 & 18,363 & 16,404 \\
\hline Liver Neoplasms & 108,497 & 218,426 & 50,019 & 82,649 & 19,102 & 18,739 \\
\hline Skin Neoplasms & 101,720 & 104,905 & 52,747 & 48,173 & 22,495 & 17,940 \\
\hline Leukemia, Myeloid & 100,328 & 92,716 & 57,083 & 46,844 & 31,693 & 24,131 \\
\hline Esophageal Neoplasms & 97,523 & 117,188 & 38,363 & 42,120 & 10,420 & 9,260 \\
\hline Stomach Neoplasms & 93,130 & 93,463 & 42,295 & 41,833 & 16,045 & 14,738 \\
\hline Genital Neoplasms, Male & 83,820 & 90,340 & 23,922 & 26,948 & 8,025 & 7,533 \\
\hline Soft Tissue Neoplasms & 69,921 & 76,536 & 39,751 & 42,221 & 21,601 & 22,571 \\
\hline Leukemia, Lymphoid & 58,720 & 52,851 & 36,000 & 30,199 & 23,160 & 18,294 \\
\hline Rectal Neoplasms & 47,173 & 61,888 & 20,528 & 27,445 & 7,123 & 8,755 \\
\hline Endocrine Gland Neoplasms & 30,117 & 29,386 & 19,665 & 17,254 & 12,892 & 10,409 \\
\hline Bone Neoplasms & 29,268 & 30,206 & 21,418 & 21,316 & 15,010 & 14,663 \\
\hline Hodgkin Disease & 26,302 & 15,765 & 17,394 & 9,643 & 10,694 & 5,493 \\
\hline Tongue Neoplasms & 18,308 & 22,568 & 8,690 & 9,505 & 3,113 & 2,830 \\
\hline Gallbladder Neoplasms & 11,625 & 13,463 & 4,260 & 4,800 & 1,113 & 1,135 \\
\hline Nasopharyngeal Neoplasms & 9,349 & 8,660 & 5,159 & 4,335 & 2,364 & 1,680 \\
\hline Intestinal Neoplasms & 8,918 & 9,275 & 4,175 & 3,780 & 1,508 & 1,243 \\
\hline Oropharyngeal Neoplasms & 5,488 & 8,918 & 2,303 & 3,488 & 593 & 755 \\
\hline Peritoneal Neoplasms & 5,183 & 5,855 & 2,188 & 2,070 & 723 & 533 \\
\hline Salivary Gland Neoplasms & 4,758 & 6,305 & 2,190 & 2,700 & 818 & 935 \\
\hline Eye Neoplasms & 2,581 & 2,955 & 1,513 & 1,440 & 843 & 652 \\
\hline Hypopharyngeal Neoplasms & 2,525 & 2,558 & 1,070 & 965 & 298 & 190 \\
\hline Lip Neoplasms & 235 & 428 & 68 & 180 & 13 & 33 \\
\hline Total & $3,634,748$ & $3,810,047$ & $1,592,960$ & $1,543,759$ & 599,284 & 498,697 \\
\hline
\end{tabular}

Source: Author's calculations based on data contained in the WHO Mortality Database. 
Table 2

Number of inpatient hospital discharges and days of care, by cancer site, 1999 and 2013

\begin{tabular}{|l|r|r|r|r|r|}
\hline Cancer site & \multicolumn{2}{|c|}{ DISCHARGES } & & \multicolumn{1}{c|}{ HOSP_DAYS } \\
\hline & \multicolumn{1}{|c|}{$\mathbf{1 9 9 9}$} & \multicolumn{1}{c|}{$\mathbf{2 0 1 3}$} & & $\mathbf{1 9 9 9}$ & \multicolumn{1}{c|}{$\mathbf{2 0 1 3}$} \\
\hline Respiratory Tract Neoplasms & \multicolumn{1}{|c|}{148,391} & 130,900 & & $1,200,377$ & 860,233 \\
\hline Breast Neoplasms & 116,916 & 67,425 & & 340,917 & 176,961 \\
\hline Colonic Neoplasms & 115,339 & 90,545 & & $1,080,513$ & 699,540 \\
\hline Genital Neoplasms, Male & 101,978 & 71,485 & & 389,868 & 170,760 \\
\hline Genital Neoplasms, Female & 98,478 & 72,100 & & 502,011 & 340,069 \\
\hline Urologic Neoplasms & 78,107 & 78,630 & & 475,148 & 424,923 \\
\hline Lymphoma, Non-Hodgkin & 48,304 & 37,225 & & 458,159 & 381,926 \\
\hline Rectal Neoplasms & 46,428 & 38,890 & & 416,847 & 295,085 \\
\hline Nervous System Neoplasms & 35,464 & 35,295 & & 257,927 & 236,890 \\
\hline Pancreatic Neoplasms & 30,799 & 34,925 & & 288,040 & 266,005 \\
\hline Stomach Neoplasms & 25,018 & 22,355 & & 270,778 & 202,975 \\
\hline Endocrine Gland Neoplasms & 20,995 & 19,375 & & 50,085 & 46,350 \\
\hline Liver Neoplasms & 14,538 & 21,920 & & 108,524 & 141,860 \\
\hline Bone Neoplasms & 14,259 & 14,355 & & 97,068 & 101,705 \\
\hline Esophageal Neoplasms & 12,753 & 11,900 & & 128,366 & 103,693 \\
\hline Skin Neoplasms & 10,627 & 8,715 & & 50,413 & 40,947 \\
\hline Hodgkin Disease & 5,534 & 3,920 & & 51,733 & 44,140 \\
\hline Total & $\mathbf{9 2 5 , 9 2 3}$ & $\mathbf{7 6 1 , 9 7 3}$ & & $\mathbf{6 , 1 6 8 , 7 7 4}$ & $\mathbf{4 , 5 3 6 , 0 7 4}$ \\
\hline
\end{tabular}

Source: Author's calculations based on data extracted from the Healthcare Cost and Utilization Project (Agency for Healthcare Research and Quality (2017)). 
Table 3

Cumulative number of research-supported and other publications, by cancer site, 1999 and 2013

\begin{tabular}{|c|c|c|c|c|c|c|}
\hline & \multicolumn{3}{|c|}{ CUM_RESEARCH_PUBS } & \multicolumn{3}{|c|}{ CUM_OTHER_PUBS } \\
\hline & 1989 & 2001 & 2013 & 1989 & 2001 & 2013 \\
\hline Endocrine Gland Neoplasms & 7,238 & 19,698 & 45,683 & 54,197 & 89,459 & 141,778 \\
\hline Breast Neoplasms & 5,795 & 22,455 & 67,139 & 33,553 & 63,902 & 112,570 \\
\hline Respiratory Tract Neoplasms & 5,387 & 15,455 & 41,012 & 55,341 & 85,914 & 132,881 \\
\hline Liver Neoplasms & 5,122 & 12,176 & 29,037 & 21,229 & 37,338 & 63,401 \\
\hline Leukemia, Myeloid & 4,678 & 12,588 & 23,522 & 14,165 & 23,965 & 36,041 \\
\hline Genital Neoplasms, Female & 4,507 & 14,290 & 36,426 & 52,815 & 80,413 & 118,927 \\
\hline Nervous System Neoplasms & 4,353 & 12,740 & 29,135 & 41,802 & 68,471 & 107,005 \\
\hline Intestinal Neoplasms & 4,261 & 15,293 & 42,889 & 30,939 & 54,612 & 95,987 \\
\hline Leukemia, Lymphoid & 3,731 & 9,393 & 18,250 & 12,040 & 19,668 & 28,795 \\
\hline Colonic Neoplasms & 3,262 & 7,928 & 16,254 & 13,909 & 20,536 & 29,189 \\
\hline Urologic Neoplasms & 3,074 & 8,436 & 18,381 & 27,805 & 45,286 & 70,826 \\
\hline Skin Neoplasms & 2,878 & 7,988 & 17,223 & 24,499 & 40,822 & 67,263 \\
\hline Genital Neoplasms, Male & 2,728 & 10,454 & 33,937 & 19,156 & 36,880 & 68,072 \\
\hline Lymphoma, Non-Hodgkin & 2,060 & 8,609 & 18,266 & 14,368 & 28,159 & 47,439 \\
\hline Bone Neoplasms & 1,531 & 4,040 & 9,561 & 33,497 & 50,164 & 74,643 \\
\hline Pancreatic Neoplasms & 1,522 & 4,490 & 12,568 & 9,507 & 16,851 & 30,963 \\
\hline Rectal Neoplasms & 1,519 & 2,651 & 4,935 & 12,391 & 17,943 & 26,781 \\
\hline Eye Neoplasms & 1,425 & 3,173 & 5,807 & 11,160 & 15,685 & 22,926 \\
\hline Hodgkin Disease & 1,290 & 2,814 & 4,373 & 12,427 & 15,957 & 19,267 \\
\hline Stomach Neoplasms & 1,173 & 4,324 & 13,624 & 21,951 & 32,729 & 48,321 \\
\hline Esophageal Neoplasms & 421 & 1,966 & 6,755 & 8,855 & 15,226 & 24,896 \\
\hline Soft Tissue Neoplasms & 418 & 1,310 & 2,377 & 3,182 & 7,977 & 15,123 \\
\hline Nasopharyngeal Neoplasms & 339 & 1,056 & 3,273 & 3,171 & 4,736 & 7,166 \\
\hline Salivary Gland Neoplasms & 279 & 741 & 1,499 & 4,703 & 7,286 & 10,711 \\
\hline Peritoneal Neoplasms & 136 & 444 & 1,360 & 2,435 & 4,504 & 8,277 \\
\hline Tongue Neoplasms & 111 & 302 & 963 & 2,415 & 3,477 & 5,052 \\
\hline Gallbladder Neoplasms & 64 & 239 & 647 & 2,024 & 3,380 & 5,080 \\
\hline Oropharyngeal Neoplasms & 55 & 271 & 851 & 1,121 & 1,975 & 3,667 \\
\hline Total & 71,346 & 207,325 & 507,760 & 546,646 & 895,316 & $1,425,060$ \\
\hline
\end{tabular}

Source: Author's calculations based on data extracted from PubMed Advanced Search Builder. 
Table 4

Average annual number of patients diagnosed in SEER 9 registries in previous 10 years, by cancer site, 1999 and 2013

\begin{tabular}{|l|r|r|}
\hline Cancer site & \multicolumn{1}{|c|}{$\mathbf{1 9 9 9}$} & \multicolumn{1}{c|}{$\mathbf{2 0 1 3}$} \\
\hline Genital Neoplasms, Male & 19,166 & 21,336 \\
\hline Breast Neoplasms & 17,183 & 20,725 \\
\hline Respiratory Tract Neoplasms & 16,902 & 18,410 \\
\hline Colonic Neoplasms & 9,462 & 9,122 \\
\hline Urologic Neoplasms & 7,652 & 10,917 \\
\hline Genital Neoplasms, Female & 6,817 & 8,053 \\
\hline Lymphoma, Non-Hodgkin & 4,553 & 6,057 \\
\hline Skin Neoplasms & 4,252 & 7,349 \\
\hline Rectal Neoplasms & 3,566 & 3,684 \\
\hline Pancreatic Neoplasms & 2,595 & 3,719 \\
\hline Stomach Neoplasms & 2,039 & 2,145 \\
\hline Endocrine Gland Neoplasms & 1,711 & 4,094 \\
\hline Nervous System Neoplasms & 1,632 & 1,937 \\
\hline Leukemia, Lymphoid & 1,496 & 2,115 \\
\hline Leukemia, Myeloid & 1,349 & 1,774 \\
\hline Liver Neoplasms & 1,116 & 2,399 \\
\hline Esophageal Neoplasms & 1,077 & 1,376 \\
\hline Hodgkin Disease & 733 & 830 \\
\hline Soft Tissue Neoplasms & 658 & 974 \\
\hline Tongue Neoplasms & 591 & 987 \\
\hline Intestinal Neoplasms & 389 & 671 \\
\hline Lip Neoplasms & 302 & 206 \\
\hline Gallbladder Neoplasms & 286 & 332 \\
\hline Salivary Gland Neoplasms & 284 & 389 \\
\hline Hypopharyngeal Neoplasms & 238 & 192 \\
\hline Bone Neoplasms & 226 & 272 \\
\hline Eye Neoplasms & 202 & 250 \\
\hline Nasopharyngeal Neoplasms & 172 & 198 \\
\hline Peritoneal Neoplasms & 88 & 187 \\
\hline Oropharyngeal Neoplasms & 119 \\
\hline
\end{tabular}

Source: Author's calculations based on data extracted from the National Cancer Institute's SEER*Stat Software. 
Table 5

Estimates of premature mortality model parameters from eq. (1):

$\ln \left(\mathrm{Y}_{\mathrm{st}}\right)=\beta_{\text {research }}$ CUM_RESEARCH_PUBS $\mathrm{s}_{\mathrm{t}, \mathrm{t}-\mathrm{k}}+\beta_{\text {other }}$ CUM_OTHER_PUBS $\mathrm{s}_{\mathrm{s}, \mathrm{t}-\mathrm{k}}$

$+\gamma \ln \left(\right.$ CASES_10_YEARS st $\left._{-}\right)+\alpha_{\mathrm{s}}+\delta_{\mathrm{t}}+\varepsilon_{\mathrm{st}}$

\begin{tabular}{|c|c|c|c|c|c|c|c|c|c|c|c|c|c|}
\hline \multirow[b]{2}{*}{ Line } & \multirow[b]{2}{*}{ lag } & \multicolumn{4}{|c|}{$\beta_{\text {research }}$} & \multicolumn{4}{|c|}{$\beta_{\text {other }}$} & \multicolumn{4}{|c|}{$\gamma$} \\
\hline & & Est. & S. E. & $Z$ & $\operatorname{Pr}>|Z|$ & Est. & S. E. & $\mathbf{Z}$ & $\operatorname{Pr}>|\mathrm{Z}|$ & Est. & S. E. & $\mathbf{Z}$ & $\operatorname{Pr}>|\mathrm{Z}|$ \\
\hline & & \multicolumn{12}{|c|}{$Y=$ YPLL75 } \\
\hline 1 & 0 & -0.001 & 0.002 & -0.73 & 0.4681 & -0.002 & 0.002 & -0.85 & 0.3938 & 0.55 & 0.26 & 2.10 & 0.0357 \\
\hline 2 & 3 & -0.002 & 0.002 & -0.99 & 0.3225 & -0.002 & 0.002 & -0.86 & 0.3914 & 0.54 & 0.26 & 2.10 & 0.0361 \\
\hline 3 & 6 & -0.004 & 0.003 & -1.51 & 0.1307 & -0.002 & 0.002 & -0.64 & 0.5199 & 0.54 & 0.26 & 2.08 & 0.0374 \\
\hline 4 & 9 & -0.008 & 0.004 & -2.04 & 0.0411 & -0.001 & 0.003 & -0.20 & 0.8408 & 0.54 & 0.26 & 2.06 & 0.0391 \\
\hline 5 & 12 & -0.013 & 0.006 & -2.23 & 0.0258 & 0.001 & 0.003 & 0.20 & 0.8442 & 0.54 & 0.27 & 2.04 & 0.0412 \\
\hline 6 & 15 & -0.018 & 0.008 & -2.17 & 0.0300 & 0.001 & 0.004 & 0.32 & 0.7484 & 0.55 & 0.27 & 2.03 & 0.0428 \\
\hline 7 & 18 & -0.019 & 0.014 & -1.40 & 0.1614 & 0.001 & 0.005 & 0.20 & 0.8399 & 0.56 & 0.28 & 2.03 & 0.0423 \\
\hline 8 & 21 & -0.015 & 0.022 & -0.68 & 0.4990 & 0.000 & 0.006 & -0.03 & 0.9732 & 0.56 & 0.27 & 2.09 & 0.0371 \\
\hline \multirow[t]{2}{*}{9} & 24 & -0.014 & 0.031 & -0.45 & 0.6559 & -0.001 & 0.007 & -0.13 & 0.8971 & 0.57 & 0.27 & 2.13 & 0.0330 \\
\hline & & \multicolumn{12}{|c|}{$Y=$ YPLL65 } \\
\hline 10 & 0 & -0.002 & 0.002 & -0.84 & 0.4012 & -0.002 & 0.002 & \begin{tabular}{|l|}
-0.92 \\
\end{tabular} & 0.3580 & 0.32 & 0.26 & 1.20 & 0.2318 \\
\hline 11 & 3 & -0.003 & 0.003 & -0.99 & 0.3229 & -0.002 & 0.003 & -0.91 & 0.3610 & 0.31 & 0.26 & 1.19 & 0.2329 \\
\hline 12 & 6 & -0.004 & 0.003 & -1.34 & 0.1787 & -0.002 & 0.003 & -0.72 & 0.4734 & 0.31 & 0.26 & 1.18 & 0.2384 \\
\hline 13 & 9 & -0.009 & 0.005 & -1.80 & 0.0726 & -0.001 & 0.004 & -0.34 & 0.7332 & 0.31 & 0.26 & 1.16 & 0.2449 \\
\hline 14 & 12 & -0.015 & 0.007 & -2.12 & 0.0340 & 0.000 & 0.004 & 0.01 & 0.9909 & 0.31 & 0.27 & 1.15 & 0.2483 \\
\hline 15 & 15 & -0.020 & 0.009 & -2.24 & 0.0249 & 0.001 & 0.005 & 0.14 & 0.8852 & 0.32 & 0.28 & 1.16 & 0.2452 \\
\hline 16 & 18 & -0.023 & 0.014 & -1.63 & 0.1023 & 0.001 & 0.006 & 0.10 & 0.9166 & 0.33 & 0.28 & 1.18 & 0.2385 \\
\hline 17 & 21 & -0.020 & 0.022 & -0.92 & 0.3593 & 0.000 & 0.007 & -0.04 & 0.9643 & 0.34 & 0.28 & 1.21 & 0.2278 \\
\hline \multirow[t]{2}{*}{18} & 24 & -0.020 & 0.031 & -0.64 & 0.5208 & -0.001 & 0.008 & -0.14 & 0.8876 & 0.34 & 0.28 & 1.22 & 0.2209 \\
\hline & & \multicolumn{12}{|c|}{$Y=$ YPLL55 } \\
\hline 19 & 0 & -0.003 & 0.004 & -0.81 & 0.4187 & -0.002 & 0.004 & \begin{tabular}{|l|}
-0.45 \\
\end{tabular} & 0.6493 & 0.03 & 0.16 & 0.19 & 0.8496 \\
\hline 20 & 3 & -0.004 & 0.006 & -0.64 & 0.5253 & -0.003 & 0.005 & -0.52 & 0.6045 & 0.03 & 0.16 & 0.21 & 0.8371 \\
\hline 21 & 6 & -0.005 & 0.008 & -0.67 & 0.5040 & -0.003 & 0.006 & -0.45 & 0.6496 & 0.03 & 0.16 & 0.20 & 0.8415 \\
\hline 22 & 9 & -0.009 & 0.010 & -0.94 & 0.3498 & -0.002 & 0.006 & -0.29 & 0.7720 & 0.03 & 0.16 & 0.19 & 0.8467 \\
\hline 23 & 12 & -0.015 & 0.011 & -1.41 & 0.1577 & -0.001 & 0.006 & -0.08 & 0.9329 & 0.04 & 0.16 & 0.22 & 0.8279 \\
\hline 24 & 15 & -0.022 & 0.011 & -1.93 & 0.0531 & 0.000 & 0.006 & 0.00 & 0.9972 & 0.05 & 0.16 & 0.29 & 0.7701 \\
\hline 25 & 18 & -0.028 & 0.012 & -2.29 & 0.0223 & 0.001 & 0.007 & 0.09 & 0.9297 & 0.07 & 0.17 & 0.38 & 0.7076 \\
\hline 26 & 21 & -0.033 & 0.016 & -2.13 & 0.0332 & 0.001 & 0.007 & 0.16 & 0.8697 & 0.08 & 0.18 & 0.43 & 0.6656 \\
\hline 27 & 24 & -0.042 & 0.021 & -2.04 & 0.0413 & 0.002 & 0.008 & 0.23 & 0.8164 & 0.09 & 0.19 & 0.46 & 0.6452 \\
\hline
\end{tabular}

Note: estimates in bold are statistically significant ( $p$-value $<.05)$. The models were estimated by weighted least squares, weighting by $(1 / 15) \Sigma_{t} Y_{s t}$. Disturbances were clustered within cancer sites. 
Table 6

Estimates of hospitalization model parameters from eq. (1):

$\ln \left(\mathrm{Y}_{\mathrm{st}}\right)=\beta_{\text {research }}$ CUM_RESEARCH_PUBS $\mathrm{s}_{\mathrm{t} t \mathrm{-k}}+\beta_{\text {other }}$ CUM_OTHER_PUBS $\mathrm{s,t- \textrm {k }}$

$+\gamma \ln \left(\right.$ CASES_10_YEARS $\left.{ }_{\mathrm{st}}\right)+\alpha_{\mathrm{s}}+\delta_{\mathrm{t}}+\varepsilon_{\mathrm{st}}$

\begin{tabular}{|c|c|c|c|c|c|c|c|c|c|c|c|c|c|}
\hline \multirow[b]{2}{*}{ Line } & \multirow[b]{2}{*}{ lag } & \multicolumn{4}{|c|}{$\beta_{\text {research }}$} & \multicolumn{4}{|c|}{$\beta_{\text {other }}$} & \multicolumn{4}{|c|}{$\gamma$} \\
\hline & & Est. & S. E. & $\mathbf{Z}$ & $\operatorname{Pr}>|Z|$ & Est. & S. E. & $\mathbf{Z}$ & $\operatorname{Pr}>|Z|$ & Est. & S. E. & $\mathbf{Z}$ & $\operatorname{Pr}>|\mathrm{Z}|$ \\
\hline & & \multicolumn{12}{|c|}{$Y=$ DISCHARGES } \\
\hline 1 & 0 & .014 & 0.003 & -5.55 & $<.0001$ & 0.006 & 0.003 & 2.22 & 0.0265 & 0.40 & 0.19 & 2.11 & 0.0348 \\
\hline 2 & 3 & -0.019 & 0.003 & -5.80 & $<.0001$ & 0.006 & 0.003 & 2.30 & 0.0215 & 0.42 & 0.18 & 2.31 & 0.0208 \\
\hline 3 & 6 & -0.025 & 0.004 & -6.91 & $<.0001$ & 0.008 & 0.003 & 2.67 & 0.0075 & 0.43 & 0.17 & 2.46 & 0.0139 \\
\hline 4 & 9 & -0.035 & 0.005 & -7.76 & $<.0001$ & 0.010 & 0.003 & 3.19 & 0.0014 & 0.44 & 0.17 & 2.58 & 0.0098 \\
\hline 5 & 12 & -0.046 & 0.006 & -7.85 & $<.0001$ & 0.012 & 0.004 & 3.43 & 0.0006 & 0.47 & 0.17 & 2.77 & 055 \\
\hline 6 & 15 & -0.062 & 0.007 & -8.40 & $<.0001$ & 0.014 & 0.004 & 3.54 & 0.0004 & 0.51 & 0.17 & 3.02 & 0.0025 \\
\hline 7 & 18 & $\mid-0.077$ & 0.015 & -5.26 & $<.0001$ & 0.016 & 0.006 & 2.77 & 0.0056 & 0.54 & 0.18 & 3.03 & 0.0024 \\
\hline 8 & 21 & & 0.027 & -3.28 & & & 0.008 & 2.05 & & 0.55 & 0.19 & 2.89 & \\
\hline \multirow[t]{2}{*}{9} & 24 & 100 & 0.037 & -2.71 & 0.0068 & 0.016 & 0.009 & 1.72 & 0.0857 & 0.55 & 0.19 & 2.89 & 0.0039 \\
\hline & & \multicolumn{12}{|c|}{$Y=$ HOSP_DAYS } \\
\hline 10 & 0 & \begin{tabular}{|l|}
-0.019 \\
\end{tabular} & 0.007 & -2.81 & 0.0049 & 0.009 & 0.003 & 2.53 & 0.0113 & 0.71 & 0.12 & 5.67 & $<.0001$ \\
\hline 11 & 3 & -0.025 & 0.009 & -2.84 & 0.0044 & 0.010 & 0.004 & 2.62 & 0.0087 & 0.71 & 0.11 & 6.23 & $<.0001$ \\
\hline 12 & 6 & -0.032 & 0.011 & -2.92 & 0.0035 & 0.011 & 0.004 & 2.71 & 0.0067 & 0.73 & 0.11 & 6.79 & $<.0001$ \\
\hline 13 & 9 & -0.038 & 0.012 & -3.17 & 0.0015 & 0.012 & 0.004 & 2.90 & 0.0038 & 0.76 & 0.11 & 7.19 & $<.0001$ \\
\hline 14 & 12 & -0.043 & 0.011 & -4.07 & $<.0001$ & 0.012 & 0.003 & 3.37 & 0.0007 & 0.78 & 0.11 & 7.28 & $<.0001$ \\
\hline 15 & 15 & -0.050 & 0.010 & -5.08 & $<.0001$ & 0.012 & 0.003 & 3.69 & 0.0002 & 0.80 & 0.11 & 7.07 & $<.0001$ \\
\hline 16 & 18 & -0.057 & 0.015 & -3.90 & $<.0001$ & 0.012 & 0.004 & 3.04 & 0.0023 & 0.80 & 0.12 & 6.44 & $<.0001$ \\
\hline 17 & 21 & -0.066 & 0.022 & -3.07 & 0.0022 & 0.013 & 0.005 & 2.48 & 0.0132 & 0.80 & 0.14 & 5.81 & $<.0001$ \\
\hline 18 & 24 & -0.080 & 0.026 & -3.05 & 0.0023 & 0.014 & 0.006 & 2.34 & 0.0195 & 0.81 & 0.14 & 5.62 & $<.0001$ \\
\hline
\end{tabular}

Note: estimates in bold are statistically significant ( $p$-value $<.05)$. The models were estimated by weighted least squares, weighting by $(1 / 15) \Sigma_{t} Y_{s t}$. Disturbances were clustered within cancer sites. 
Figure 1

Number of years of potential life lost before age 75, 4 cancer sites, 1999 and 2013

300,000

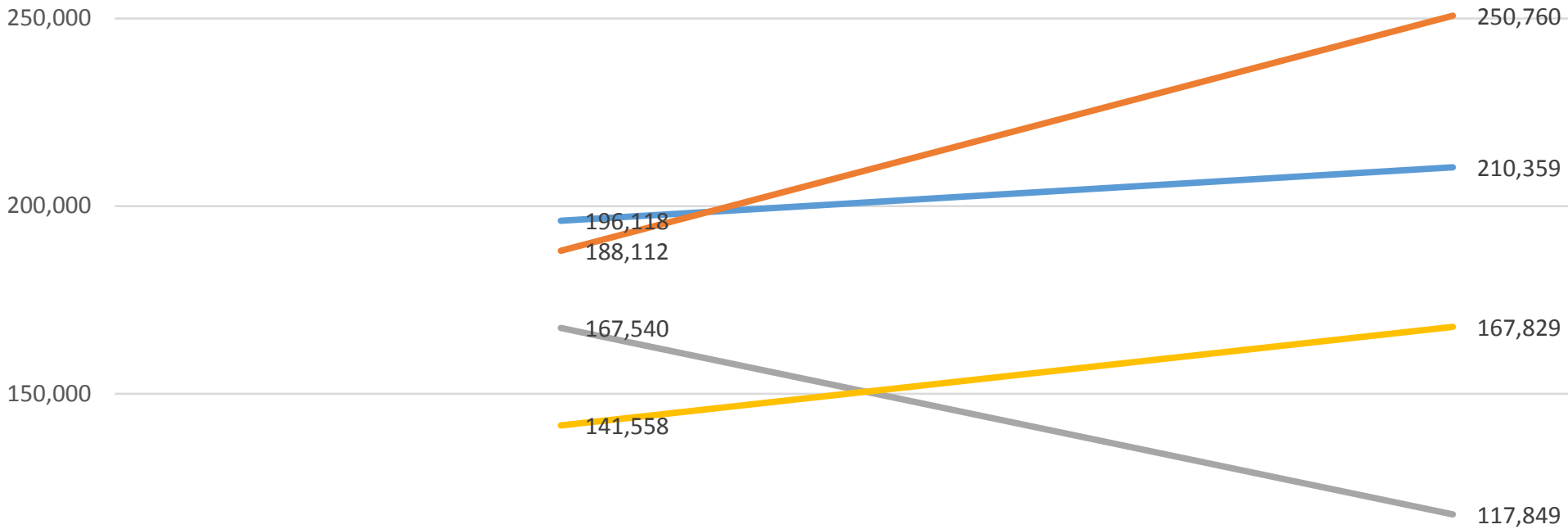

100,000

50,000 


\section{Figure 2}

Cumulative number of research-supported publications, 4 cancer sites, 1989-2013

50,000

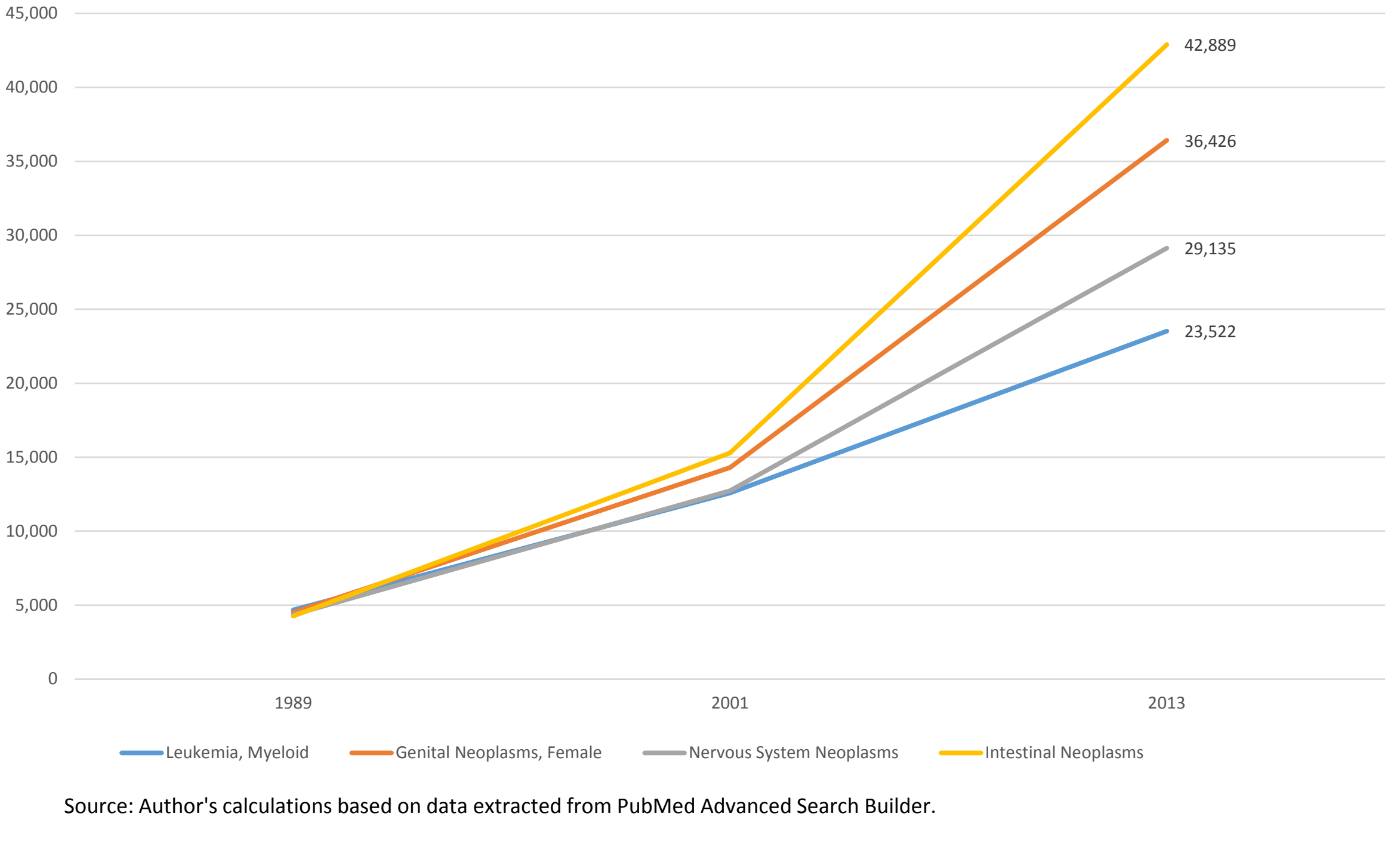


Figure 3

Estimates of $\beta_{\text {research }}$ from eq. (1) where dependent variable is $\ln (Y P L L 75)$

$-0.02$

0.00

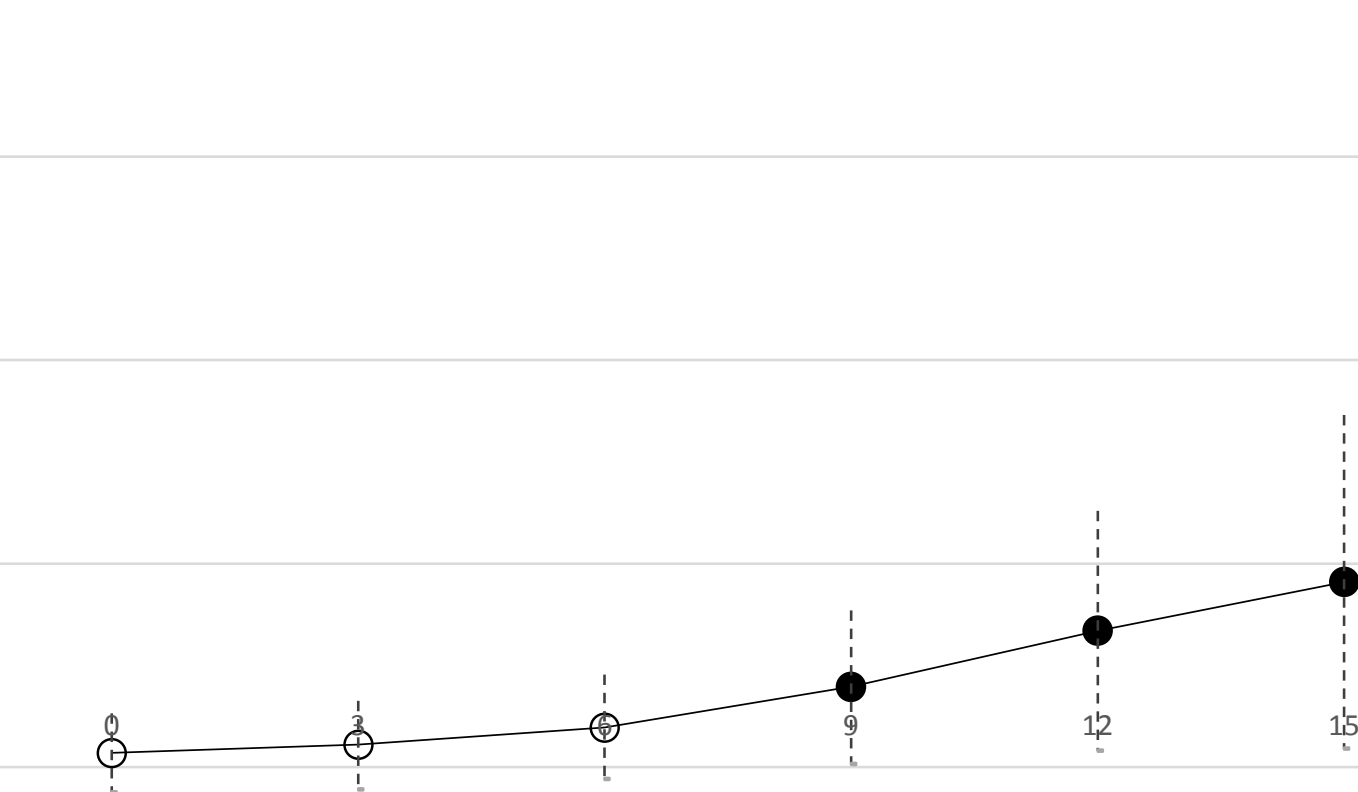

0.02

Note: scale is inverted

Vertical lines represent $95 \%$ confidence intervals

Estimates represented by solid circles are statistically significant ( $p$-value $<.05)$

0.04 
Figure 4

Estimates of $\beta_{\text {research }}$ from eq. (1) where dependent variable is $\ln (Y P L L 55)$

$-0.09$ k

$-0.08$

$-0.07 \quad$ Note: scale is inverted

Vertical lines represent $95 \%$ confidence intervals

$-0.06$

Estimates represented by solid circles are statistically significant ( $p$-value $<.05$ )

$-0.05$

$-0.04$

$-0.03$

$-0.02$

$-0.01$

0.00

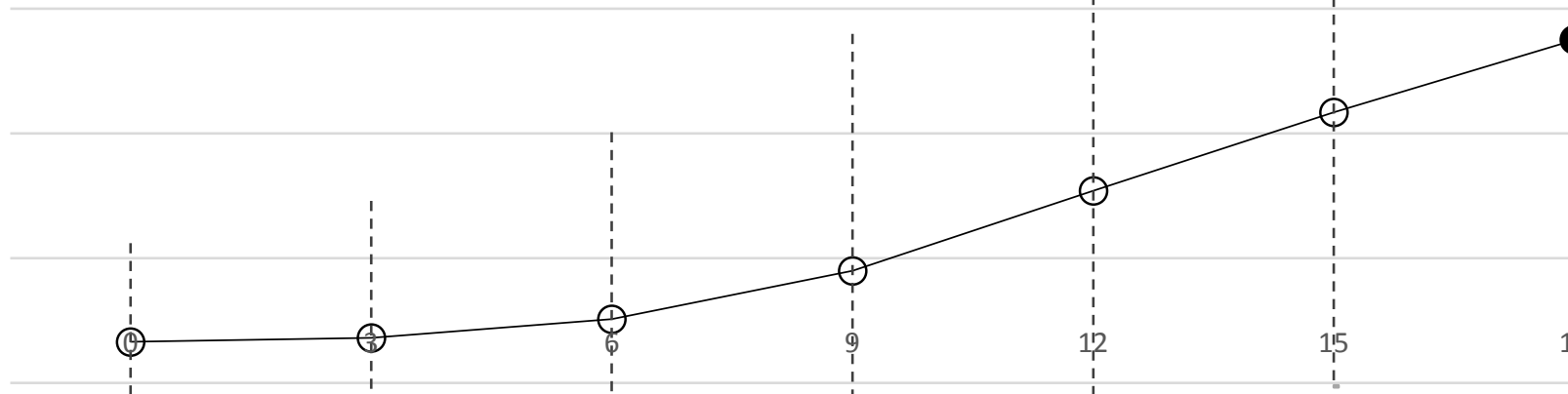

0.01 
Figure 5

\section{Estimates of $\beta_{\text {research }}$ from eq. (1) where dependent variable is $\ln (D I S C H A R G E S)$}

Note: scale is inverted

Vertical lines represent $95 \%$ confidence intervals

Estimates represented by solid circles are statistically significant ( $p$-value $<.05)$

$-0.04$

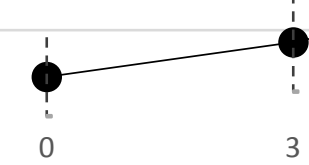


PublMed.gov

US National Library of Medicin National Institutes of Health
PubMed
Cos

Colonic Neoplasms[MeSH Terms]

Create RSS Create alert Advanced
Search

Help

\begin{abstract}
Article
types

Clinical Trial

Review

Customize ...

Text

availability

Format: Summary - Sort by: Publication

Date -

Send to -

\section{Search results}

Items: 1 to 20 of 67435
\end{abstract}

Abstract

Free full text

Full text

PubMed

Commons

Reader comments

Trending articles

Publication

dates

5 years

10 years

Custom range...

Species

Humans

Other Animals

\section{Clear all}

Show additional filters Li X, Zhang G, Wang Y, Elgehama A, Sun Y, Li L, Gu Y, Guo W, Xu Q.

Biomed Pharmacother. 2017 Mar;87:366-374. doi:

10.1016/j.biopha.2016.12.103.

PMID: 28068625

Similar articles

Mid-term oncologic outcome of a novel approach for locally

3. advanced colon cancer with neoadjuvant chemotherapy and surgery.

Arredondo J, Baixauli J, Pastor C, Chopitea A, Sola JJ, González I, A-Cienfuegos J, Martínez P, Rodriguez J, Hernández-Lizoain JL. Clin Transl Oncol. 2017 Mar;19(3):379-385. doi: 10.1007/s12094-016-1539-4. PMID: 27496023

Similar articles
Filters: Manage Filters

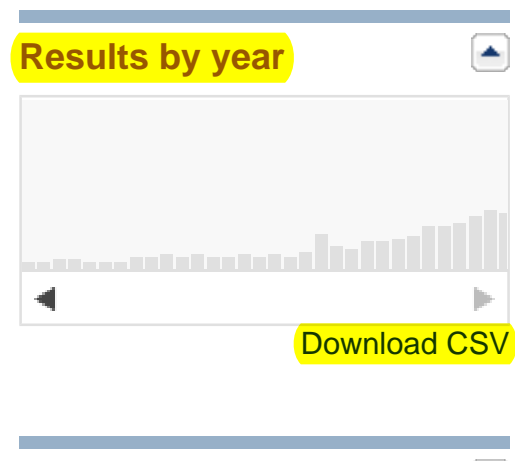

Titles with your search terms

Helicobacter pylori infection is an in [Cancer Causes Control. 2017]

The molecular characteristics of colonic [J Pathol Clin Res. 2016]

Diverticular Disease and

[Asian Pac J Cancer Prev. 2016] See more...

Stochastic phenotypic interconversion in tumors can generate

4. heterogeneity.

Simone G.

Eur Biophys J. 2017 Mar;46(2):189-194. doi: 10.1007/s00249-016-1190-6.

PMID: 27942765

Similar articles

Betalains increase vitexin-2-O-xyloside cytotoxicity in CaCo-2

5. cancer cells.

Farabegoli F, Scarpa ES, Frati A, Serafini G, Papi A, Spisni E, Antonini E, Benedetti S, Ninfali P.

Food Chem. 2017 Mar 1;218:356-364. doi: 10.1016/j.foodchem.2016.09.112.
Recent Activity

$\underline{\text { Turn Off }} \underline{\text { Clear }}$

Find related data

Database:

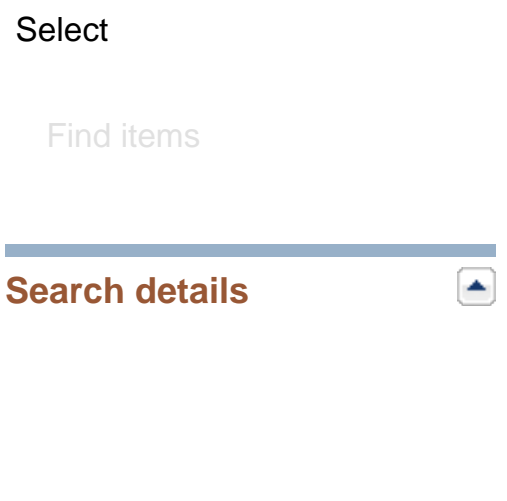

See more...

Colonic Neoplasms[MeSH
Terms] (67435) $\quad$ PubMed

Q Colonic Neoplasms[MeSH Major Topic] (49940) PubMed 